\title{
Comparison of two systems of tonoplast purification from tobacco cells of suspension culture BY-2
}

\section{Tingzhuo Chen ${ }^{1,3}$, Anastasia Kirpichnikova1, Yulia Mikhaylova ${ }^{2}$, and Maria Shishova ${ }^{1}$}

\begin{abstract}
1Department of Plant Physiology and Biochemistry, Faculty of Biology, Saint Petersburg State University, Universitetskaya nab., 7-9, Saint Petersburg, 199034, Russian Federation

${ }^{2}$ Laboratory of Biosystematics and Cytology, Komarov Botanical Institute, Russian Academy of Sciences, ul. Professora Popova, 2, Saint Petersburg, 197376, Russian Federation ${ }^{3}$ Chengdu New Sun Crop Science Co., Ltd., No. 35, Gongye Five Road, Hengshan Town, Pujiang, Chengdu, 611630, Sichuan, People's Republic of China

Address correspondence and requests for materials to Maria Shishova, mshishova@mail.ru
\end{abstract}

\section{Abstract}

The tonoplast is an intracellular membrane, important for numerous functions of the vacuoles in plant cells. Transport, signaling, enzymatic activity and other processes of the tonoplast are the focus of a wide spectrum of studies. Multiple advanced analyses demand highly purified vacuoles or vesicles of the tonoplast membrane fraction. Since 1960 several approaches have been developed for such purification, but new goals and new model objects require adjustment of already existing techniques. The presented investigation aimed to compare two methods of tonoplast membrane fraction purification from tobacco suspension cell culture BY-2 (Nicotiana tabacum L., cv Bright Yellow) based on sucrose and sucrose/sorbitol gradients. The functional activity of obtained purified tonoplast fractions was measured by the hydrolytic activity of vacuolar $\mathrm{H}^{+}$-ATPase and $\mathrm{H}^{+}$-PPase.

Keywords: tonoplast, vesicle fraction, purification, V-ATPase, $\mathrm{H}^{+}$-PPase.

Citation: Chen, T., Kirpichnikova, A.

Mikhaylova, Yu., Shishova, M. 2020. Comparison of two systems of tonoplast purification from tobacco cells of suspension culture BY-2. Bio. Comm. 65(2): 178-186. https://doi.org/10.21638/ spbu03.2020.204

Authors' information: Tingzhuo Chen, $\mathrm{PhD}$, Junior Researcher, orcid.org/0000-00015143-6128; Anastasia Kirpichnikova, Junior Researcher, orcid.org/0000-0001-5133-5175 Yulia Mikhaylova, PhD, Junior Researcher, orcid.org/0000-0001-9278-0937; Maria Shishova, Dr. of Sci. in Biology, Professor, orcid.org/0000-0003-3657-2986

Manuscript Editor: Farida Minibayeva, Laboratory of Redox Metabolism, Kazan Institute of Biochemistry and Biophysics, Kazan Scientific Center, Russian Academy of Sciences, Kazan, Russia

Received: October 27, 2019;

Revised: January 7, 2020;

Accepted: February 14, 2020.

Copyright: () 2020 Chen et al. This is an open-access article distributed under the terms of the License Agreement with Saint Petersburg State University, which permits to the authors unrestricted distribution, and self-archiving free of charge.

Funding: The work was partly supported by the Russian Foundation for Basic Research (No. 19-04-00655).

Competing interests: The authors have declared that no competing interests exist.

\section{Introduction}

The tonoplast is an endogenous membrane surrounding the central vacuole which fulfills a crucial role in the biochemistry and physiology of a plant cell. It participates in the generation and maintenance of cell turgor. It is involved in elongation growth as well as different processes of autophagy and even cell death (Hatsugai et al., 2015; Kruger and Schumacher, 2018). Vacuoles vary significantly in number and size due to the cell type and developmental stage (Zhang, Hicks and Raikhel, 2014). Vacuoles participate in nutrition storage, detoxification, adaptation to salt stress and pathogen attack (Martinoia et al., 2007; Trentmann and Haferkamp, 2013). The origin of the plant cell central vacuole is still debated (Kruger and Schumacher, 2018). It might originate from the ER (Endoplasmic reticulum) subdomains and/or the trans-Golgi network (Mesquita, 1969; Marty, 1978). Central vacuole biogenesis is closely linked to actin-myosin cytoskeleton reorganization and is regulated by 1NAA (1-naphthylacetic acid), a synthetic auxin analogue; this indicates a possible mechanism involved in the elongation growth, triggered by auxin (Scheuring et al., 2016).

The tonoplast is enriched by different transporters. Special attention is always paid to tonoplast proton pumps. $\mathrm{H}^{+}$-ATPase and $\mathrm{H}^{+}$-PPase are known to use the energy of macroergic bonds for generation of the proton gradient important for secondary active transport of different ions and compounds (Dettmer et al., 2006; Schumacher, 2006). The direction of transport is important to provide $\mathrm{pH}$ and 
$\mathrm{Ca}^{2+}$ cytosolic homeostasis and to equalize the osmotic potential between the vacuole and cytosol.

Investigation of tonoplast morphology and crossinteraction between the tonoplast and other intracellular membranes might be visualized with freeze-etching electron microscopy and 3D high-voltage electron microscopy. Tonoplast biochemical composition alteration during development or stress adaptation requires modern systemic approaches like proteomics (Trentmann and Haferkamp, 2013). Thus, correct vacuole preparation and the procedure of tonoplast membrane fraction enrichment acquire a special importance.

One of the first methods to obtain vacuoles by osmotic lysis from protoplasts was developed in the 1960s (Cocking, 1960). It was adjusted for vacuole preparation from different plant tissues and plant species (Gregory and Cocking, 1966; Wagner and Siegelman, 1975). Recently the method was corrected for gathering vacuoles from Arabidopsis leaves (Trentmann and Haferkamp, 2013). But some observations narrow the application of this method. The first one concerns the use of enzymes for protoplast isolation. The procedure requires three to five hours to digest the cell wall, so it is hardly applicable for the investigation of fast cell responses triggered by light signals, stress factors, etc. Another approach to obtain a reasonable yield of protoplasts is gentle mechanical disruption of the tissue (Leigh and Branton, 1976; Salyaev et al., 1981). Thin slicing is suitable for different plant tissues, including very robust ones such as a storage beetroot of Beta vulgaris. Further vacuole purification after osmotic lysis of protoplasts is usually provided by a gradient of sorbitol, ficoll, $\mathrm{KCl}$, metrizamide, etc. The stability and viability of vacuoles depend significantly on the gradient nature and $\mathrm{pH}$ level. However, these substances used for osmotic lysis might cause alteration in the tonoplast enzyme activity and even loss of peripheral proteins. Hence, the purity of the vacuoles and tonoplast fraction obtained is high and can be used for further highly specific proteome analysis (Trentmann and Haferkamp, 2013).

Nevertheless, for the investigation of functional activity of the tonoplast, especially for the analysis of the activity of its enzymes and transporters, another method of purification was used widely. Tonoplast vesicles from homogenized plant tissues are purified by ultracentrifugation in a density gradient. According to a number of studies, membrane fractions enriched with tonoplast are supposed to be located between $14 \%$ and $26 \%$ sucrose layers (Leonard and Vanderwoude, 1976; Tankelyun et al, 1986; Briskin, Leonard and Hodges,1987; Larsson, Widell and Kjellbom, 1987; Tankelyun, 1998; Shakhova and Tankelyun, 2008). This method of purification was used to detect activity of different enzymes including tonoplast $\mathrm{H}^{+}$-ATPase and proton PP-ase (Mettler and Leonard, 1979; Dupont, Bennett and Spanswick, 1982;
Churchill and Sze, 1983). The sucrose-gradient centrifugation is not ideal to obtain a fraction free of endomembrane contamination, and thus it consistently was replaced by another approach. The problem was solved by the method of purification based on the sorbitol/sucrose gradient centrifugation (Maeshima and Yoshida, 1989; Maeshima, 2000).

Taken together, purified tonoplast/vacuole could be obtained by a few methods suitable for a wide spectrum of model objects represented by different plant organs and tissues. But still the method type has to be tested for each plant material and might require some adjustments. For example, in cells of suspension culture, because of the continuous shaking, the mechanical properties of the cell wall might differ from those of plant cells of native tissues; in this case the application of enzymatic or slicing methods would be rather questionable. The presented investigation is aimed to compare two methods of tonoplast membrane fraction purification from tobacco suspension cell culture based on sucrose and sucrose/sorbitol gradients.

\section{Material and methods}

Plant material. Etiolated suspension tobacco cell culture BY-2 (Nicotiana tabacum L. cv. Bright Yellow) was used for tonoplast isolation. Initially this culture was obtained from tobacco leaf mesophyll cells and cultivated in modified Murashige-Skoog (MS) salt medium (Murashige and Skoog, 1962), containing $30 \mathrm{~g} \mathrm{l}^{-1}(0.09 \mathrm{M})$ sucrose and $0.2 \mathrm{mg} \mathrm{l}^{-1}$ 2,4-dichlorophenoxyacetic media (Kobayashi, Niino and Kobayashi, 2006). BY-2 cells in suspension show synchronized development and grow relatively slowly (18 days is the full life cycle), which makes this line attractive for different type of studies (Hasezawa, 1983; Nagata, Nemoto and Hasezawa, 1992; Nagata and Kumagai, 1999; Zazimalova, Petrášek and Morris 2003; Nagata, Hasezawa and Inze, 2004; Petrášek and Zazimalova, 2006). BY-2 suspension was cultivated in liquid media on an orbital shaker $(110 \mathrm{rpm})$ at $25^{\circ} \mathrm{C}$ in the darkness. Cells were transferred to fresh medium every 18 days. For tonoplast isolation 14-day-old cells were used at the stage of elongation growth (Petrášek and Zazimalova, 2006).

Sucrose-density gradient (SDG) method. This method was previously developed for maize coleoptiles (Tankelyun, 1998; Shakhova and Tankelyun, 2008). The main scheme for tonoplast enrichment is shown in Figure 1 . All steps were conducted at $4{ }^{\circ} \mathrm{C}$. We grinded $30 \mathrm{~g}$ of cells in a homogenizator Wisd23 HG-15D (5 min, $10,000 \mathrm{rpm})$ in $30 \mathrm{~mL}$ of SDG-I medium (0.4 M Sucrose, $50 \mathrm{mM}$ Tris/MES pH 7.8, $5 \mathrm{mM} \mathrm{Na} \mathrm{N}_{2}$ EDTA, $0.03 \mathrm{M}$ ascorbic acid, $2.5 \mathrm{mM}$ DTT). We added $20 \mathrm{~mL}$ of SDG1 medium to the homogenate and performed two-step centrifugation: $100 \mathrm{~g}$ for $5 \mathrm{~min}$ and $4200 \mathrm{~g}$ for $10 \mathrm{~min}$ 


\section{The outline of the tonoplast isolation via sucrose density-gradient}

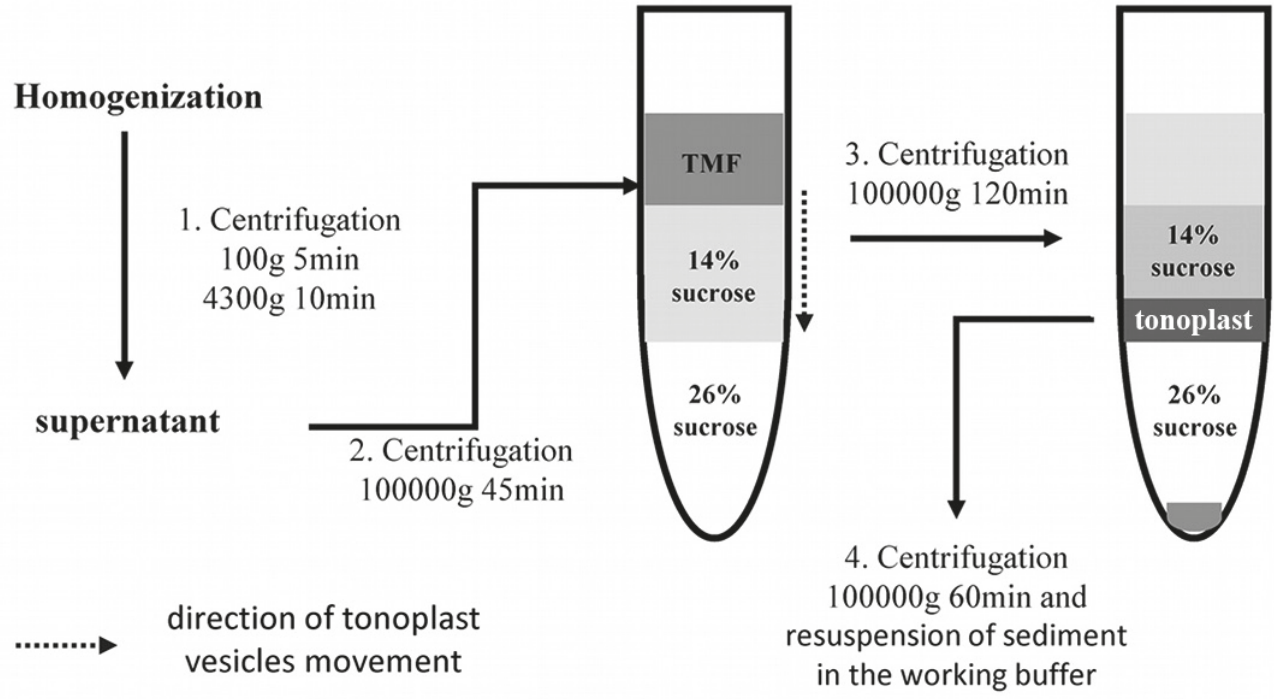

Fig. 1. The scheme of tonoplast isolation via the sucrose density gradient (SDG) method.

\section{The outline of the tonoplast isolation via sucrose-sorbitol system.}

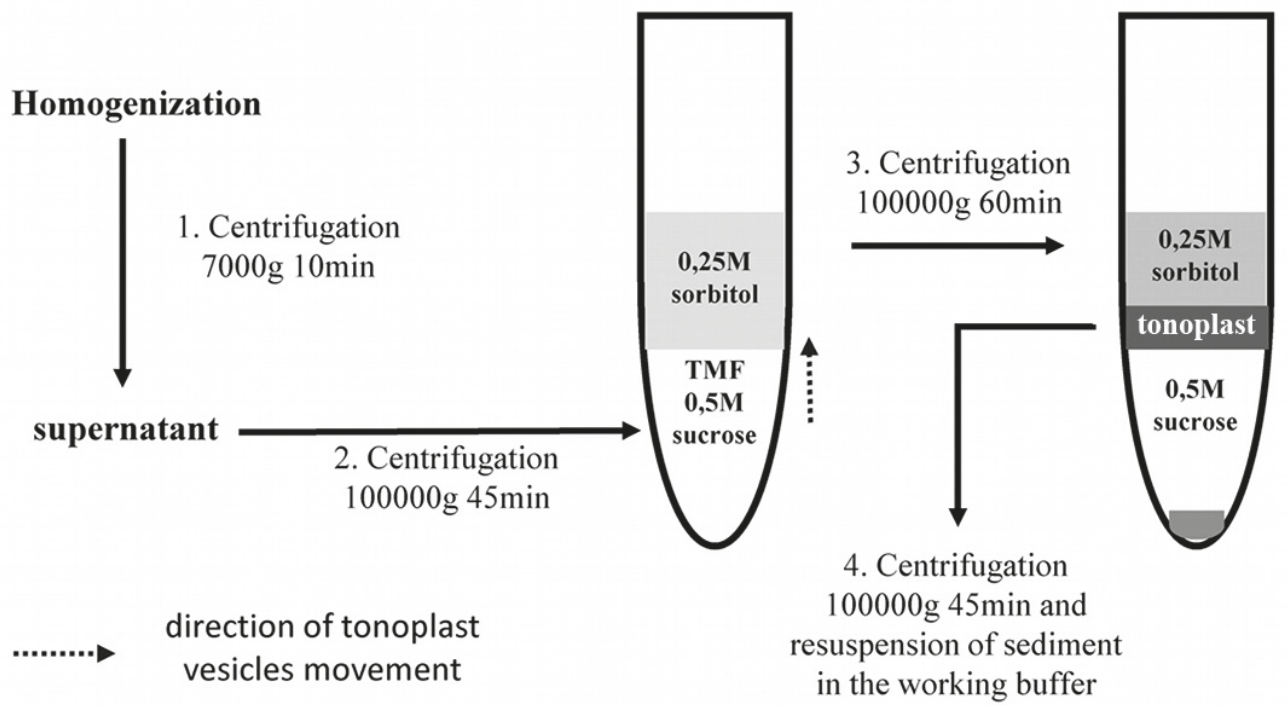

Fig. 2. The scheme of tonoplast isolation via the sucrose-sorbitol system (SSS) method

(MPW-350R centrifuge). The sediment, containing unbroken cells, nuclei, mitochondria and plastids, was discarded. The supernatant of accumulated cell membranes was centrifuged at 100,000g for $45 \mathrm{~min}$ (ultracentrifuge Beckman Avanti J-30I). The obtained sediment, consisting of total microsomal fraction (TMF), was resuspend- ed in medium SDG-II ( $0.2 \mathrm{M}$ sucrose $5 \mathrm{mM}$ Tris-Mes $\mathrm{pH}$ 7.2, $1 \mathrm{mM} \mathrm{Na}_{2}$ EDTA, $1 \mathrm{mM}$ DTT) in a Potter-Elvehjem homogenizator. For the gradient, $14 \%$ and $26 \%$ sucrose solutions prepared in $1 \mathrm{mM}$ Tris-Mes buffer $\mathrm{pH} 7.2$ were gently layered and then $1 \mathrm{~mL}$ of resuspended TMF was added on the top. After centrifugation (100,000g for $2 \mathrm{~h}$ ) 
the targeted tonoplast-enriched fraction (TEF) was collected on the border of the sucrose solutions. Next, the TEF was resuspended in medium SDG-II and centrifuged again at 100,000g for $60 \mathrm{~min}$. The obtained sediment contained the purified TEF. The purified TEF was suspended in medium SDG-II and stored at $-80^{\circ} \mathrm{C}$.

Sucrose-sorbitol system (SSS) method. Initially the SSS method was developed by Maeshima and Yoshida (1989) for mung bean hypocotyl tissues. In this investigation it was adjusted for tobacco cell suspension culture. The scheme of tonoplast-enrichment vesicle fraction purification by the sucrose-sorbitol method is shown in Figure 2. All steps were carried out at $4{ }^{\circ} \mathrm{C}$. Cells $(30 \mathrm{~g})$ were grinded with a homogenizer Wisd23 HG-15D (5 min, 10,000 rpm) in $30 \mathrm{~mL}$ of medium SSS-I (0.25 M Sorbitol, $50 \mathrm{mM}$ Tris/MES pH 7.5, $1 \mathrm{mM}$ EGTA, $2 \mathrm{mM}$ DTT, $1 \%$ (W/V) PVP, $0.2 \%$ (W/V) $\mathrm{BSA}$ ). The homogenate was centrifuged $10 \mathrm{~min}$ at $7000 \mathrm{~g}$ (MPW-350R centrifuge). The sediment was discarded and the supernatant was centrifuged at $100,000 \mathrm{~g}$ for 45 min (ultracentrifuge Beckman Avanti J-30I). The sediment, containing TMF, was collected in medium SSS-II (0.5 M sucrose, $20 \mathrm{mM}$ Tris/MES pH 7.5, $1 \mathrm{mM}$ EGTA, $2 \mathrm{mM} \mathrm{MgCl}_{2}, 2 \mathrm{mM}$ DTT) and transferred to a Potter-Elvehjem homogenizer. Resuspended TMF was applied on the top of sorbitol medium SSS-III (0.25 M sorbitol, $20 \mathrm{mM}$ Tris/MES pH 7.5, 1 mM EGTA, $2 \mathrm{mM}$ $\mathrm{MgCl}_{2}, 2 \mathrm{mM}$ DTT). This sucrose-sorbitol system was centrifuged at 100,000g for $60 \mathrm{~min}$. The vesicle fraction enriched by tonoplast (TEF) was collected at the border between sucrose and sorbitol. It was then diluted with medium SSS-III and centrifuged at 100,000g for $45 \mathrm{~min}$. The sediment was resuspended in SSS-III and frozen at $-80^{\circ} \mathrm{C}$ until further analysis.

Protein Determination. For a quantitative protein assay M. Bradford's (1976) micromethod was employed. This method is based on specific sorption of Coomassie brilliant blue G-250 dye by proteins. A protein sample was added to a solution of the dye in phosphoric acid and ethanol. Extinction was measured at $595 \mathrm{~nm}$ on a Spekol-1300 spectrophotometer (Analytic Jena). For a calibration curve we used the ovalbumin solution in $150 \mathrm{mM}$ sucrose and $10 \mathrm{mM}$ Tris-MES pH 7.2.

ATPase and PPase assays. The hydrolytic activity of membrane $\mathrm{H}^{+}$-ATPase or $\mathrm{H}^{+}$-pyrophosphatase was measured by the level of inorganic phosphorus (Pi) resulting from enzymatic hydrolysis of ATP or inorganic pyrophosphate (PPi), respectively. Hydrolytic activity was tested at the appropriate optimal $\mathrm{pH}$ : 6.0 for plasma membrane ATPase; 7.2 for tonoplast $\mathrm{H}^{+}$-ATPase and $\mathrm{H}^{+}$-pyrophosphatase (Briskin, 1991).

A hydrolytic reaction was started by adding $25 \mu \mathrm{L}$ of membrane fraction to $125 \mu$ of a reaction mixture containing $90 \mathrm{mM}$ Tris-Mes, $15 \mathrm{mM}$ ATP or sodium pyrophosphate, $0.25 \mathrm{M} \mathrm{KCl}, 15 \mathrm{mM} \mathrm{MgCl}_{2}$. Eppendorf microtubes with the reaction mixture were incubated for $30 \mathrm{~min}$ at $37^{\circ} \mathrm{C}$ in a water thermoshaker. For nonenzyme ATP hydrolysis, test reaction mixture without $\mathrm{KCl}$ and $\mathrm{MgCl}_{2}$ was used. $\mathrm{K}^{+}$and $\mathrm{Mg}^{2+}$ ions are mandatory for membrane $\mathrm{H}^{+}$-ATPase activity. The hydrolytic reaction was stopped by adding $50 \mu \mathrm{l}$ of $20 \%$ trichloracetic acid and cooling in an ice bath.

Inorganic phosphorus in the reaction mixture was determined spectrophotometrically (Lindeman, 1958). The method is based on the formation of the phosphomolybdic acid complex, which becomes colored by a reducer $\left(\mathrm{SnCl}_{2}\right)$. Staining developed for $30 \mathrm{~min}$ and was measured at $750 \mathrm{~nm}$ on Spekol-1300.

Inhibitor analysis. For the determination of possible contamination of the tonoplast vesicle fraction with plasma membrane, further inhibitors were used: $\mathrm{Na}_{3} \mathrm{VO}_{4}$ (sodium orthovanadate) - a specific inhibitor of $\mathrm{H}^{+}$-ATPase plasmalemma ( $\mathrm{pH}$ 6.0) - and bafilomycin - an inhibitor of tonoplast $\mathrm{H}^{+}$-ATPase ( $\mathrm{pH}$ 7.2).

Statistics. All experiments were done in at least three biological and three analytic replicates. Standard deviation was calculated using the STDEV function in the package STDEV. S (Std Dev, Standard Deviation). Statistical significance was calculated using GraphPad Prism 7 software. Average values and error of mean are shown in the diagrams. Significance of the differences was calculated with ANOVA (One-way analysis of variance). Statistically significant differences $(\mathrm{P} \leq 0.05)$ are marked as*; Values of $\mathrm{P} \leq 0.01$ of statistical significance are marked $a s^{\star *}$.

\section{Results and discussion}

The results of modern proteome analysis revealed the importance of the vacuole/tonoplast isolation, which affects the quality and quantity of identified proteins (Trentmann and Haferkamp, 2013). It is no less important to obtain a highly purified fraction for the analysis of tonoplast activity.

Two methods developed for tonoplast purification were compared in this investigation. The first one is based on tonoplast vesicle separation from other plant cell membranes according to their density. According to literature data this parameter varies as follows: tonoplast, $1.10-1.12 \mathrm{~g} / \mathrm{cm}^{3}$, Golgi membranes, $1.12-1.15 \mathrm{~g} /$ $\mathrm{cm}^{3}$, rough endoplasmic reticulum, $1.15-1.17 \mathrm{~g} / \mathrm{cm}^{3}$, thylakoids, $1.16-1.18 \mathrm{~g} / \mathrm{cm}^{3}$, plasma membrane, $1.14-$ $1.17 \mathrm{~g} / \mathrm{cm}^{3}$, and mitochondrial membranes, $1.18-1.20 \mathrm{~g} /$ $\mathrm{cm}^{3}$ (Leonard and Vanderwoude, 1976; Briskin, Leonard and Hodges, 1987; Larsson, Widell and Kjellbom, 1987).

After grinding, tobacco cell homogenate was freed of unbroken cells, nuclei, mitochondria and plastids by low speed centrifugation (Fig. 1). The collected supernatant was used to sediment total microsomal fraction. The tonoplast was separated from the TMF with the 


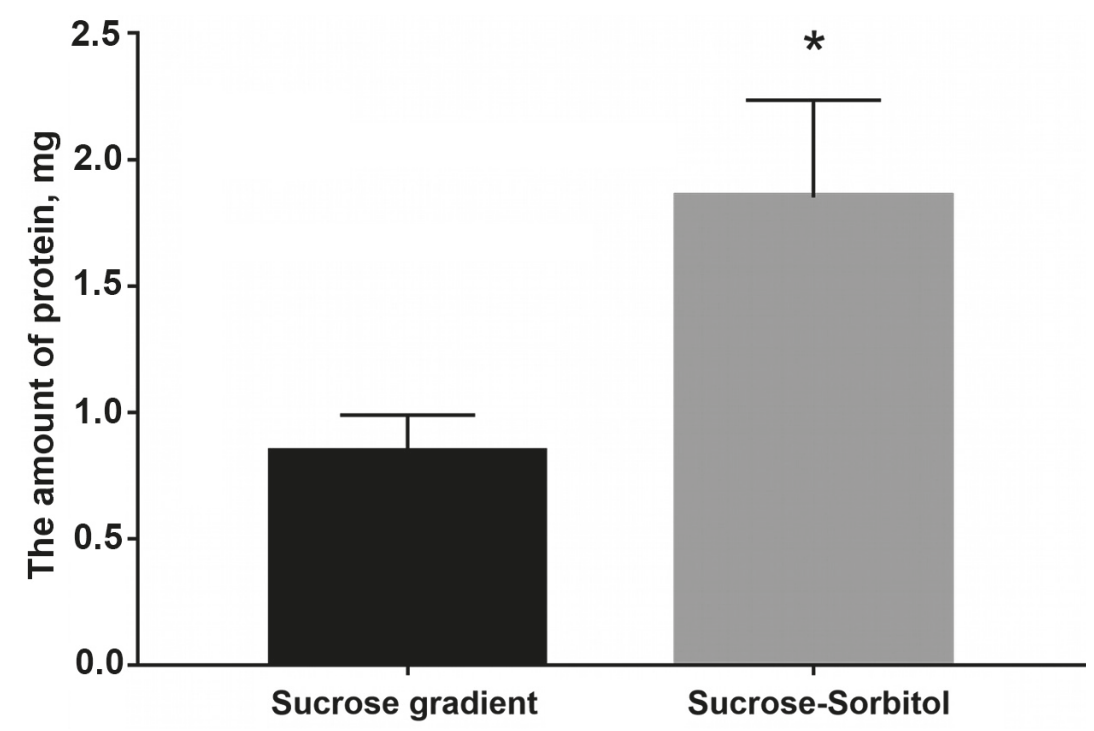

Fig. 3. The amount of proteins in tonoplast-enriched fractions obtained by SDG and SSS methods.

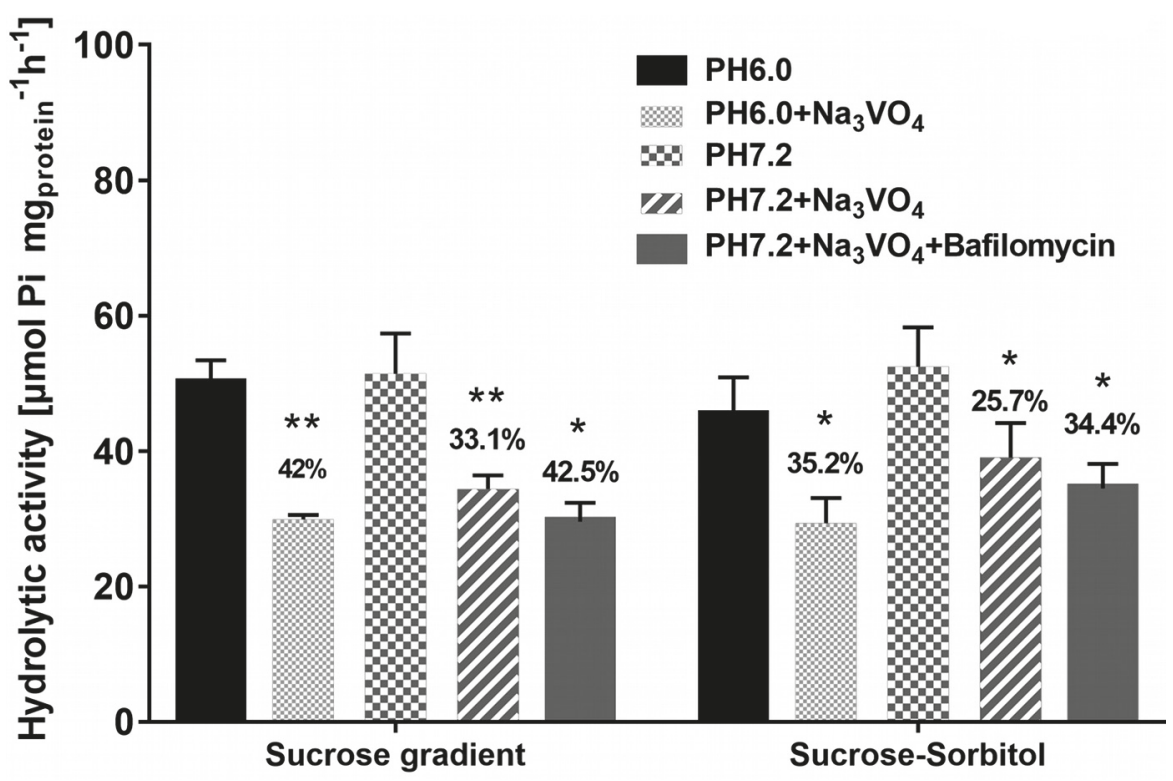

Fig. 4. Effects of $\mathrm{pH}$ and inhibitors on ATPase activity of total microsomal fractions obtained as parts of SDG and SSS methods.

sucrose gradient on the border between $14 \%$ and $26 \%$ sucrose solutions. The TEF was concentrated by ultracentrifugation and used for further analysis.

Alternatively, tobacco cells were homogenized and prepared as shown in Figure 2 until TMF. In this approach the microsomal fraction was separated via the sucrose/sorbitol system. The tonoplast vesicles accumulated on the border between sorbitol and sucrose layers. As in the SDG method, the tonoplast fraction was sedimented by ultracentrifugation and used for comparison.

Firstly, both SDG and SSS tonoplast fractions were used for a protein assay. As shown in Figure 3 the SSS method gave $55 \%$ greater protein accumulation. This higher protein yield positively characterized the sucrose/sorbitol system.

Further analysis focused on the quality of tonoplast fractions, i.e., the degree of purification. Fraction quality was estimated by inhibitor analysis, based on the activity of marker enzymes. The plasma membrane usually is the main contaminant of a tonoplast fraction. The marker enzyme of the plasma membrane is P-type $\mathrm{H}^{+}$-ATPase with optimum $\mathrm{pH}$ 6.0, inhibited by vanadate $\left(\mathrm{Na}_{3} \mathrm{VO}_{4}\right)$. Vanadate ions selectively bind in the active center with a carboxylic group of aspartic acid residue instead of phosphorus (Boldyrev, 1990; Wach, Ahlers and Gräber, 1990). Vacuolar V-type $\mathrm{H}^{+}$-ATPase is con- 


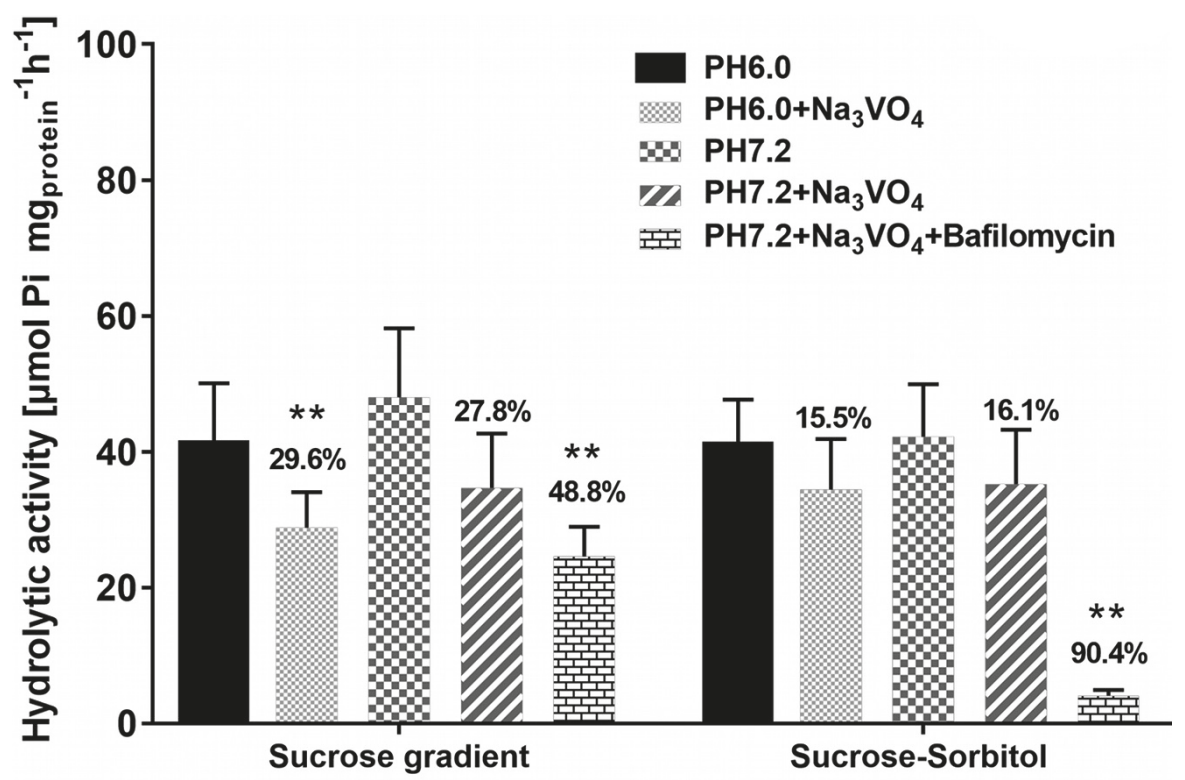

Fig. 5. Effects of $\mathrm{pH}$ and inhibitors on ATPase activity of tonoplast-enriched fractions obtained by SDG and SSS methods.

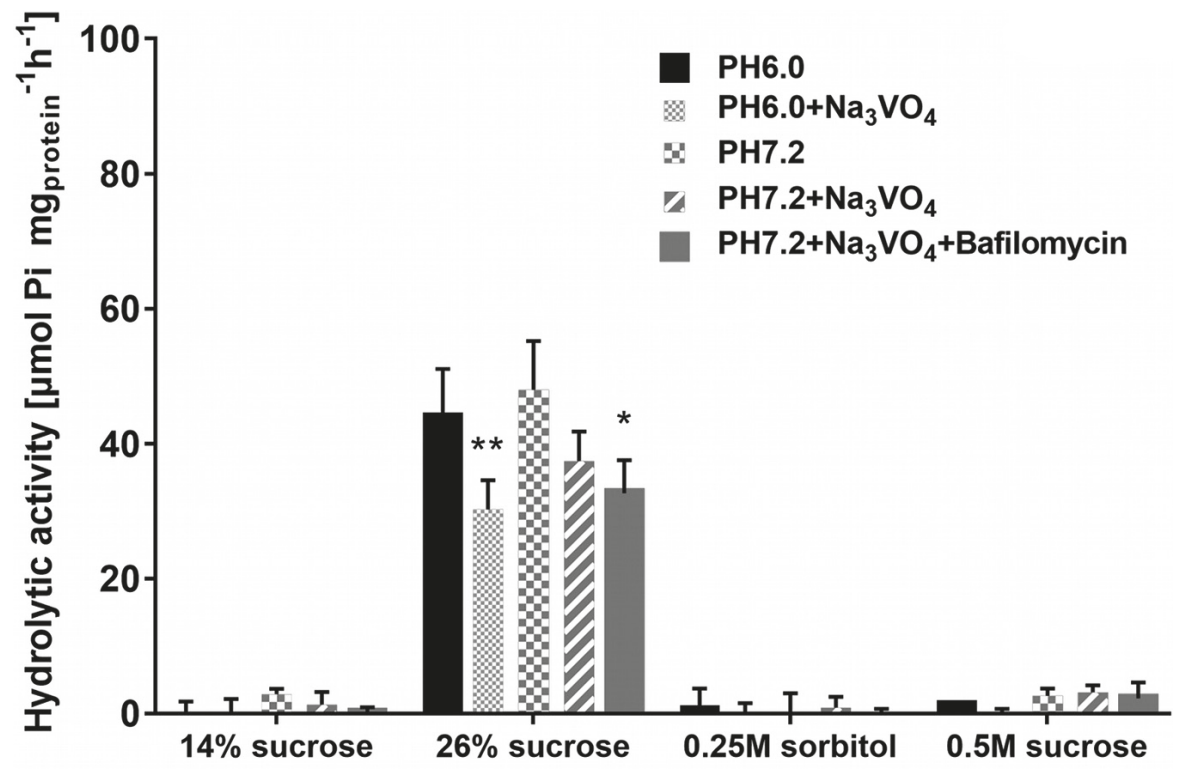

Fig. 6. Effects of $\mathrm{pH}$ and inhibitors on ATPase activity of vesicles obtained from working solution using two different methods of tonoplast enrichment. The SDG method used $14 \%$ and $26 \%$ sucrose solution. The SSS method used $0.25 \mathrm{M}$ sorbitol and $0.5 \mathrm{M}$ sucrose solution.

sidered a marker enzyme of the tonoplast. The multisubunit protein complex has optimum $\mathrm{pH}$ of 7.2. The selective inhibitor of a V-type tonoplast $\mathrm{H}^{+}$-ATPase is bafilomycin (Ohkuma et al., 1993). In case of implication of both enzymes for fraction characterization, the determination of Pi accumulation as a result of ATPase activity at different $\mathrm{pH}$ and with the presence of inhibitors would indicate a possible contamination of the tonoplast fraction.

Initially $\mathrm{H}^{+}$-ATPase activity was tested in total microsomes obtained from tobacco cells, and it later was used for purification. Figure 4 presented data on a hydrolytic assay of TMF. In collected microsomal membranes P-type and V-type $\mathrm{H}^{+}$-ATPase activities were detected. Vanadate and bafilomycin were effective at inhibiting Pi release. Mean values were similar in both of the schemes used.

The hydrolytic activity of the tonoplast fractions obtained by the two different methods was quite similar, at about 40 moles Pi per mg of protein in $1 \mathrm{~h}$ (Fig. 5). Vanadate decreased the ATPase activity of SDG-obtained TEF by $29.6 \%$ (pH 6.0) and $27.8 \%$ (pH 7.2) (Fig. 5). SSS- 


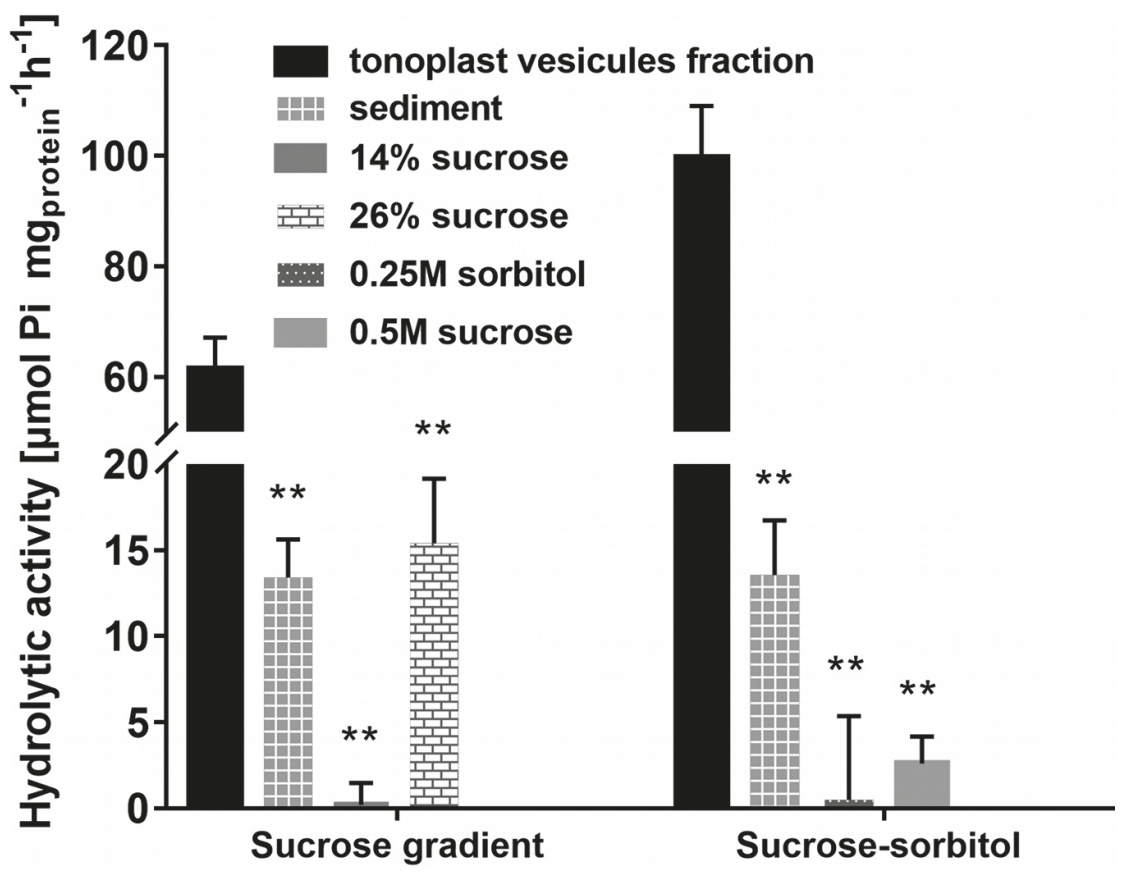

Fig. 7. Pyrophosphatase activity of tonoplast-enriched fractions and vesicles from working solutions and sediments, obtained as parts of SDG and SSS methods.

obtained TEF was almost half as sensitive to vanadate: by $15.5 \%$ and $16.1 \%$ at $\mathrm{pH} 6.0$ and 7.2 , respectively, but differences were not statistically significant. This proves that plasma membrane contamination in TEF obtained via the SSS method is minor. Bafilomycin, known as a highly selective inhibitor of V-type $\mathrm{H}^{+}$-ATPases, decreased fraction hydrolytic activity by $21 \%$ in SDG-TEF and by $74.3 \%$ in SSS-TEF. Thus after sucrose/sorbitol purification, the vesicle fraction was highly enriched with tonoplast.

Subsequent analysis concerned detection of residual $\mathrm{H}^{+}$-ATPase activity in sucrose solutions with the SDG method and sucrose/sorbitol media with the SSS method after gathering the tonoplast fraction. Presented data (Fig. 6) revealed that sucrose/sorbitol media were free of any membrane contamination, which would demonstrate $\mathrm{H}^{+}$-ATPase activity. The same absence of activity was estimated for the $14 \%$ sucrose solution. Accumulation of Pi was detected only in the $26 \%$ sucrose layer. Application of vanadate and bafilomycin caused inhibition. Thus this part of the gradient is characterized by leftovers of plasmalemma and tonoplast. According to obtained data, the sucrose/sorbitol scheme is optimal to decrease the loss of tonoplast.

An additional enzyme that could be suggested as a marker for tonoplast is $\mathrm{H}^{+}$-pyrophosphatase. Determination of its activity is presented in Figure 7. TEFs showed maximal activity, but it was higher with the SSS method. The sucrose gradient approach was characterized by half amplitude activity in the $26 \%$ sucrose layer, which was shown to be contaminated by plasma mem- brane and tonoplast, according to the hydrolytic test (Fig. 6).

\section{Conclusion}

Obtained data indicated that the sucrose/sorbitol method is preferable for purification of the tonoplast fraction from tobacco suspension cell culture. This method turned out to be better in terms of the vacuolar membrane fraction quality, and less time-consuming as well. The tonoplast vesicle fraction was suitable for the investigation of the activity of both vacuolar proton pumps: $\mathrm{H}^{+}$-ATPase and $\mathrm{H}^{+}$-pyrophosphatase. Marker enzymes revealed sensitivity to specific inhibitors and optimum $\mathrm{pH}$ value.

\section{References}

Boldyrev, A. A. 1990. Introduction to biomembranology. Izdatelstvo MGU, Moscow. 208 p. (In Russian)

Bradford, M. 1976. A rapid and sensitive method for the quentation of microgram quantities of protein utilizing the principle of protein-dye binding. Analytical Biochemistry 1(2):248-254. https://doi.org/10.1016/00032697(76)90527-3

Briskin, D. P. and Reynolds-Niesman, I. 1991. Determination of H/ATP Stoichiometry for the plasma membrane $\mathrm{H}$ ATPase from red beet (Beta vulgaris L.) storage tissue. Plant Physiology 95(1):242-250. https://doi.org/10.1104/ pp.95.1.242

Briskin, D.P., Leonard, R. T., and Hodges, T. K. 1987. Isolation of the plasma membrane: Membrane markers and general principles. Methods in Enzymology 148:542-558. https://doi.org/10.1016/0076-6879(87)48053-1 
Churchill, K. A. and Sze, H. 1983. Anion-sensitive, $\mathrm{H}^{+}$-pumping ATPase in membrane vesicles from oat roots. Plant Physiology 71:610-617. https://doi.org/10.1104/pp.71.3.610

Cocking, E. C. 1960. A method for the isolation of plant protoplasts and vacuoles. Nature 187:962-963. https://doi. org/10.1038/187962a0

Dettmer, J., Hong-Hermesdorf, A., Stierhof, Y.-D., and Schumacher, K. 2006. Vacuolar $\mathrm{H}^{+}$-ATPase activity is regulated for endocytic and secretory trafficking in Arabidopsis. Plant Cell 18:715-730. https://doi.org/10.1105/ tpc.105.037978

Dupont, F. M., Bennett, A. B., and Spanswick, R. M. 1982 Localization of a protontranslocating ATPase on sucrose gradient. Plant Physiology 70:1115-1119. https://doi. org/10.1104/pp.70.4.1115

Gregory, D.W. and Cocking, E. C. 1966. Studies on isolated protoplasts and vacuoles. I. General properties. Journal of Experimental Botany 17:57-67. https://doi. org/10.1093/jxb/17.1.57

Hasezawa, S. 1983. Hormonal control of elongation of tobacco cells derived from protoplasts. Plant Cell Physiology 24:127-132. https://doi.org/10.1093/oxfordjournals. pсp.a076507

Hatsugai, N., Yamada, K., Goto-Yamada, S., and HaraNishimura, I. 2015. Vacuolar processing enzyme in plant programmed cell death. Frontiers in Plant Science 6:234. https://doi.org/10.3389/fpls.2015.00234

Kobayashi, T., Niino, T., and Kobayashi, M. 2006. Cryopreservation of Tobacco BY-2 Suspension Cell Cultures Using an Encapsulation - Simple Prefreezing Method. Biotechnology in Agriculture and Forestry, pp. 329-337 in: T. Nagata, K. Matsuoka, D. Inzé (eds) Tobacco BY-2 Cells: From Cellular Dynamics to Omics. Biotechnology in Agriculture and Forestry, vol 58. Springer, Berlin, Heidelberg. https://doi.org/10.1007/3-540-32674-X_21

Kruger, F. and Schumacher, K. 2018. Pumping up the volume - vacuole biogenesis in Arabidopsis thaliana. Seminars in Cell \& Developmental Biology 80:106-112. https:// doi.org/10.1016/j.semcdb.2017.07.008

Larsson, C., Widell, S., and Kjellbom, P. 1987. Preparation of high-purity plasma membranes. Methods in Enzymology 148:558-568. https://doi.org/10.1016/00766879(87)48054-3

Leigh, R. A. and Branton, D. 1976. Isolation of vacuoles from root storage tissue of Beta vulgaris L. Plant Physiology 58:656-662. https://doi.org/10.1104/pp.58.5.656

Leonard, R.T. and Vanderwoude, W.J. 1976. Isolation of plasma membranes from corn roots by sucrose density gradient centrifugation: an anomalous effect of ficoll. Plant Physiology 57(1):105-114. https://doi.org/10.1104/ pp.57.1.105

Lindeman, W. 1958. Observations on the behavior of phosphate compounds in Chlorella at the transition from dark to light. Processings of the II International Conference of UN on the Peaceful Uses of Atomic Energy 24:8-15.

Maeshima, M. 2000. Vacuolar $\left.\mathrm{H}^{+}\right)$-pyrophosphatase. Biochimica et Biophysica Acta (BBA) - Biomembranes 1465(1-2):3751. https://doi.org/10.1016/S0005-2736(00)00130-9

Maeshima, M. and Yoshida, S. 1989. Purification and properties of vacuolar membrane proton-translocating inorganic pyrophosphatase from mung bean. Journal of Biological Chemistry 264(33):20068-20073.

Martinoia, E., Maeshima, M., and Neuhaus, H. E. 2007. Vacuolar transporters and their essential role in plant metabolism. Journal of Experimental Botany 58(1):83-102. https://doi.org/10.1093/jxb/erl183

Marty, F. 1978. Cytochemical studies on GERL provacuoles, and vacuoles in root meristematic cells of Euphorbia. Pro- ceedings of the National Academy of Sciences of the United States of America 75(2):852-856. https://doi.org/10.1073/ pnas.75.2.852

Mesquita, J.F. 1969. Electron microscope study of the origin and development of the vacuoles in root-tip cells of Lupinus albus L.Journal of Ultrastructure Research 26(3-4):242-250. 5320(69)80004-3

https://doi.org/10.1016/S0022-

Mettler, I. J. and Leonard, R. T. 1979. Ion transport in isolated protoplasts from tobacco suspension cells: I. General characteristics. Plant Physiology 63(1):183-190. https:// doi.org/10.1104/pp.63.1.183

Murashige, T. and Skoog, F. 1962 A revised medium for rapid growth and bioassay with tobacco tissue cultures. Physiologia Plantarum 15:473-497. https://doi. org/10.1111/j.1399-3054.1962.tb08052.x

Nagata, T. and Kumagai, F. 1999. Plant cell biology through the window of the highly synchronized tobacco By-2 cell line. Methods in Cell Science 21:123-127. https://doi. org/10.1023/A:1009832822096

Nagata, T., Hasezawa, and S., Inze, D. (Eds.) 2004. Tobacco By-2 Cells. 347 pp. Springer, Berlin, Heidelberg. https:// doi.org/10.1007/978-3-662-10572-6

Nagata, T., Nemoto, Y., and Hasezawa, S. 1992. Tobacco By- 2 cell line as the 'Hela' cells in the cell biology of higher plants. International Review of Cytology 132:1-30. https://doi.org/10.1016/S0074-7696(08)62452-3

Ohkuma, S., Shimizu. S., Noto., M., Sai, Y., Kinoshita, K., and Tamura, H.-O. 1993. Inhibition of cell growth by bafilomycin $\mathrm{A} 1$, a selective inhibitor of vacuolar $\mathrm{H}(+)$-ATPase. In Vitro Cellular \& Developmental Biology - Animal 29(11):862-866. https://doi.org/10.1007/BF02631364

Petrášek, J. and Zažímalová, E. 2006 The BY-2 Cell Line as a Tool to Study Auxin Transport. pp. 107-117 In: Nagata T., Matsuoka K., Inzé D. (eds) Tobacco BY-2 Cells: From Cellular Dynamics to Omics. Biotechnology in Agriculture and Forestry, vol. 58. Springer, Berlin, Heidelberg. https://doi.org/10.1007/3-540-32674-X_8

Salyaev, R. K., Kuzevanov, V. Ya., Khaptagaev, S. B., and Kopytchuk, V. N. 1981. Isolation and purification of vacuoles and vacuolar membranes from plant cells. Russian Journal of Plant Physiology 28(6):1295-1305. (In Russian)

Scheuring, D., Löfke, C., Krüger, F., Kittelmann, M., Eisa, A., Hughes, L., Smith, R. S., Hawes, C., Schumacher, K., and Kleine-Vehn, J. 2016. Actin-dependent vacuolar occupancy of the cell determines auxin-induced growth repression. Proceedings of the National Academy of Sciences of the United States of America 113:452-457. https://doi. org/10.1073/pnas.1517445113

Schumacher, K. 2006. Endomembrane proton pumps: connecting membrane and vesicle transport. Current Opinion in Plant Biology 9:595-600. https://doi.org/10.1016/j. pbi.2006.09.001

Shakhova, N. V. and Tankelyun, O. V. 2008. Some characteristics of ATP and pyrophosphate-dependent transport of $\mathrm{H}^{+}$ions in the endomembrane fraction from coleoptile cells of maize seedlings. Vestnik Sankt-Peterburgskogo Universiteta. Seriya 3: Biologiya 1:69-79. (In Russian)

Tankelyun, O.V. 1998. Properties of pyrophosphatase and ATPase activity of membrane fractions containing tonoplast isolated from corn coleoptile cells. Vestnik SanktPeterburgskogo Universiteta. Seriya 3: Biologiya 2(10):97103. (In Russian)

Tankelyun, O. V., Chirkova, T.V., Tishchenko, N. N., and Magomedov, I. M. 1986. Enzymes. pp. 50-71. in V. V. Polevoy, G. B. Maksimov, N. F. Sinyutina (Eds.) Methods for the study of plant cell membranes. Izdatelstvo Leningradskogo Universiteta, Leningrad. (In Russian) 
Trentmann, O. and Haferkamp, I. 2013. Current progress in tonoplast proteomics reveals insights into the function of the large central vacuole. Frontiers in Plant Science 4:34. https://doi.org/10.3389/fpls.2013.00034

Wach, A., Ahlers, J., and Gräber, P. 1990. The H+-ATPase of the plasma membrane from yeast. Kinetics of ATP-hydrolysis in native membranes, isolated and reconstituted enzymes. European Journal of Biochemistry 189:675-682. https://doi.org/10.1111/j.1432-1033.1990.tb15536.x
Wagner, G. J. and Siegelman, H. W. 1975. Large-scale isolation of intact vacuoles and isolation of chloroplast from protoplasts of mature plant tissues. Science 190:1298-1299. https://doi.org/10.1126/science.190.4221.1298

Zažímalová, E., Petrášek, J., and Morris, D. A. 2003. The dynamics of auxin transport in tobacco cells. Bulgarian Journal of Plant Physiology. Special issue:207-224.

Zhang, C., Hicks, G. R., and Raikhel, N. V. 2014. Plant vacuole morphology and vacuolar trafficking. Frontiers in Plant Science 5:476. https://doi.org/10.3389/fpls.2014.00476 